\title{
EDITORIAL
}

\section{Flora das cangas de Carajás: taxonomia preparando novos caminhos}

O presente fascículo encerra a série sobre a Flora das cangas da Serra dos Carajás, desenvolvida nos últimos quatro anos sob a coordenação conjunta do Museu Paraense Emílio Goeldi e do Instituto Tecnológico Vale (Viana et al. 2016). Este quarto volume especial da Rodriguésia dedicado à flora das cangas de Carajás completa a coleção das monografias taxonômicas das famílias de plantas que foram registradas nos afloramentos ferruginosos da Floresta Nacional de Carajás e do Parque Nacional dos Campos Ferruginosos, no estado do Pará. Este volume conta com dez artigos de famílias de briófitas e 23 de famílias de angiospermas, somando 398 espécies tratadas. São incluídos também três artigos apresentando a síntese florística dos grandes grupos de plantas focalizados durante o projeto: briófitas (Oliveira-da-Silva \& Ilkiu-Borges 2018), samambaias e licófitas (Salino et al. 2018) e fanerógamas (Mota et al. 2018).

Somando os quatro volumes dedicados à Flora das cangas da Serra dos Carajás, foram produzidas monografias taxonômicas padronizadas para 164 famílias (22 de briófitas, 22 de pteridófitas, uma de gimnosperma e 119 de angiospermas) totalizando 1094 espécies. Trata-se do maior esforço coordenado para documentar sistematicamente a flora de uma área na Amazônia brasileira, que contou com a colaboração de 145 taxonomistas envolvidos nas autorias dos artigos.

O nível atual de conhecimento sobre flora das cangas de Carajás é diferenciado no contexto da flora amazônica e também em relação às demais formações de canga no Brasil. Essa base é um marco fundamental para o planejamento eficaz para a conservação das espécies deste ambiente único e ameaçado, e também para assentar estudos variados sobre a biodiversidade na região a diferentes níveis. Longe de ser um encerramento, celebramos o início de uma nova fase de estudos, agora baseados em nomes e circunscrições autoritativas das espécies da região.

Agradecemos ao corpo editorial da Rodriguésia, todos os autores e revisores dos artigos, curadores dos herbários, funcionários do ICMBio, Vale S/A, Museu Paraense Emílio Goeldi e Instituto Tecnológico Vale, o apoio essencial para cumprir este compromisso tão importante para o avanço da botânica no País.

$$
\text { Pedro Lage Viana }{ }^{1}
$$

Editor responsável Flora das cangas de Carajás

\author{
Ana Maria Giulietti-Harley ${ }^{2}$ \\ Editora convidada
}

\footnotetext{
Museu Paraense Emílio Goeldi, Coord. Botânica, Av. Perimetral 1901, 66077-830, Belém, PA, Brasil. pedroviana@museu-goeldi.br

${ }^{2}$ Instituto Tecnológico Vale, R. Boaventura da Silva 955, 66055-090, Belém, PA, Brasil. ana.giulietti@pq.itv.org, anagiulietti@hotmail.com
} 


\section{Referências}

Oliveira-da-Silva FO \& Ilkiu-Borges AL (2018) Briófitas (Bryophyta e Marchantiophyta) das cangas de Carajás, Pará, Brasil. Rodriguésia 69: 1405-1416.

Mota NFO, Watanabe MTC, Zappi DC, Hiura AL, Pallos J, Viveros RS, Giulietti AM \& Viana PL. (2018) Cangas da Amazônia: a vegetação única de Carajás evidenciada pela lista de fanerógamas. Rodriguésia 69: 1435-1488.
Salino A, Arruda AJ \& Almeida TE (2018) Ferns and lycophytes from Serra dos Carajás, an Eastern Amazonian mountain range. Rodriguésia 69: 1417-1434.

Viana PL, Mota NFO, Gil ASB, Salino A, Zappi DC, Harley RM, Ilkiu-Borges AL, Secco RS, Almeida TE, Watanabe MTC, Santos JUM, Trovó M, Maurity C \& Giulietti AM (2016) Flora of the cangas of the Serra dos Carajás, Pará, Brazil: history study area and methodology. Rodriguésia 67: $1107-1124$. 